\title{
Metode Systematic Literature Review untuk Identifikasi Platform dan Metode Pengembangan Sistem Informasi di Indonesia
}

\author{
E Triandini* ${ }^{* 1}$, S Jayanatha ${ }^{2}$, A Indrawan ${ }^{3}$, G W Putra ${ }^{4}$, B Iswara ${ }^{5}$ \\ 1,2,3,4,5 Program Studi Sistem Informasi, STMIK STIKOM Bali, Jl. Raya Puputan No. \\ 86 Renon, Denpasar, Indonesia
}

E-mail: evi.triandini11@gmail.com¹,sadujayanatha@gmail.com², ayik6000@gmail.com ${ }^{3}$,werlaputra97@gmail.com ${ }^{4}$, iswarabayu95@gmail.com ${ }^{5}$

Masuk: 9 Januari 2019, direvisi: 12 Februari 2019, diterima: 16 Februari 2019

\begin{abstract}
Abstrak. Sistem informasi adalah cara-cara yang diorganisasi untuk mengumpulkan, memasukkan, mengolah, dan menyimpan data, serta untuk menyimpan, mengelola, mengendalikan, dan melaporkan informasi sedemikian rupa sehingga sebuah organisasi dapat mencapai tujuan yang telah ditetapkan. Pengembangan sistem informasi memiliki metodemetode yang beragam. Metode yang dapat digunakan untuk pengembangan sistem antara lain metode terstruktur dan berorientasi objek. Berdasarkan metode tersebut, suatu sistem akan dikembangkan untuk dapat dijalankan pada platform berbasis web, mobile, atau desktop. Saat ini belum diketahui berapa banyak sistem informasi yang dikembangkan oleh kedua metode tersebut, demikian juga belum diketahui juga berapa banyak aplikasi yang dijalankan oleh ketiga platform tersebut. Penelitian ini bertujuan untuk mengidentifikasi platform dan metode pengembangan sistem informasi di Indonesia yang datanya diperoleh dari jurnal yang terkait pada tahun 2013-2018. Metode yang digunakan dalam penelitian ini adalah Metode Systematic Literature Review (SLR). Metode SLR digunakan untuk mengidentifikasi, mengkaji, mengevaluasi, dan menafsirkan semua penelitian yang tersedia dengan bidang topik fenomena yang menarik, dengan pertanyaan penelitian tertentu yang relevan. Dengan penggunaan Metode SLR dapat dilakukan review dan identifikasi jurnal secara sistematis, yang pada setiap prosesnya mengikuti langkah-langkah atau protokol yang telah ditetapkan. Hasil penelitian menunjukkan bahwa platform yang dominan digunakan dalam pengembangan sistem informasi adalah berbasis website sedangkan metode dominan digunakan dalam menyelesaikan pengembangan sistem informasi adalah metode terstruktur.
\end{abstract}

Kata kunci: Systematic Literature Review; metode terstruktur; metode berorientasi objek

Abstract. Information systems are ways that are organized to collect, enter, process and store data, as well as store, manage, control, and report information in such a way that an organization can achieve its intended purpose. The development of information systems has various methods. Methods that can be used for system development include structures methods and object-oriented methods. Based on these methods, a system will be developed to run on web, mobile or desktop platforms. At present, it is not known how many information systems are developed by two methods, moreover it is not known how many applications are run by three platforms. The method used in this study is Systematic Literature Review (SLR) method. The objectives of SLR include being used to identify, review, evaluate, and interpret all 
available research with interesting phenomenon topic areas, with certain relevant research questions. The SLR method reviews and identifies the journal systematically, in each of its processes following the steps or protocols that have been set. Data used in this study are data from 2013-2018 research results. The results of this study are the dominant platform used in developing information systems is website-based and the dominant method used in completing information system development is structured method

Keywords: Systematic Literature Review; structured method; object-oriented method

\section{Pendahuluan}

Sistem informasi adalah cara-cara yang diorganisasi untuk mengumpulkan, memasukkan, mengolah, dan menyimpan data serta untuk menyimpan, mengelola, mengendalikan, dan melaporkan informasi sedemikian rupa sehingga sebuah organisasi dapat mencapai tujuan yang telah ditetapkan [1]. Sistem informasi di perusahaan atau organisasi saat ini terus berkembang. Jika dahulu sistem informasi masih bersifat konvensional dengan pencatatan dan berkas-berkas hardcopy, kini mulai terkomputerisasi sehingga semua proses bisnis yang terjadi dilakukan dan dibantu pelaksanaannya dengan menggunakan komputer [2]-[4]. Dengan adanya kemajuan sistem informasi, setiap perusahaan atau organisasi berlomba-lomba membuat sistem informasi yang kompleks dan bermanfaat untuk proses bisnis mereka [4].

Pengembangan sistem informasi memiliki metode-metode yang beragam mulai dari metode terstruktur hingga berbasis objek. Dari metode pengembangan inilah nantinya akan ditentukan, pada perangkat manakah sistem informasi akan berjalan. Apakah pada perangkat berbasis web, mobile, atau desktop. Pemilihan perangkat di mana sistem akan berjalan merupakan proses yang penting, karena ketersediaan sistem untuk pengguna dapat diukur dari penggunaan perangkat atau platform di mana sistem itu berjalan. Mengingat pentingnya metode pengembangan sistem informasi dan pemilihan platform di mana sistem itu berjalan, maka pada penelitian ini dikumpulkan data-data dari penelitian terdahulu tentang sistem informasi untuk mengetahui metode pengembangan dan platform sistem informasi.

Data-data yang dikumpulkan adalah jurnal yang membahas tentang pengembangan sistem informasi dari tahun 2013 hingga 2018. Data-data tersebut diidentifikasi menggunakan metode Systematic Literature Review (SLR). Dengan penggunaan Metode SLR dapat dilakukan review dan identifikasi jurnal secara sistematis yang pada setiap prosesnya mengikuti langkah-langkah atau protokol yang telah ditetapkan [5]-[7]. Selain itu, Metode SLR dapat menghindarkan dari identifikasi yang bersifat subjektif dan diharapkan hasil identifikasinya dapat menambah literatur tentang penggunaan Metode SLR dalam identifikasi jurnal [7][8].

\section{Kerangka Teoritis}

\subsection{Systematic Literature Review (SLR)}

2.1.1 Pengertian SLR. Systematic Literature Review merupakan istilah yang digunakan untuk merujuk pada metodologi penelitian atau riset tertentu dan pengembangan yang dilakukan untuk mengumpulkan serta mengevaluasi penelitian yang terkait pada fokus topik tertentu [9].

2.1.2 Tujuan SLR. Penelitian SLR dilakukan untuk berbagai tujuan, di antaranya untuk mengidentifikasi, mengkaji, mengevaluasi, dan menafsirkan semua penelitian yang tersedia dengan bidang topik fenomena yang menarik, dengan pertanyaan penelitian tertentu yang relevan [6][7][9]. SLR juga sering dibutuhkan untuk penentuan agenda riset, sebagai bagian dari disertasi atau tesis, serta merupakan bagian yang melengkapi pengajuan hibah riset [10]. 


\section{Metodologi Penelitian}

\subsection{Objek Penelitian}

Objek penelitian ini adalah sistem informasi. Pengambilan sistem informasi sebagai objek penelitian memiliki beberapa alasan sebagai berikut:

1. Adanya perubahan dalam penerapan sistem informasi yang dulunya masih bersifat konvensional dengan pencatatan dan berkas-berkas fisik, kini mulai terkomputerisasi.

2. Pengembangan sistem informasi dapat dilakukan di berbagai platform, antara lain web, desktop, dan mobile.

3. Pengembangan sistem informasi memiliki metode-metode yang beragam.

\subsection{Metode Penelitian}

3.2.1. Research Question. Research Question atau pertanyaan penelitian dibuat berdasarkan kebutuhan dari topik yang dipilih. Berikut ini adalah pertanyaan penelitian dalam penelitian ini:

RQ1. Apa perangkat yang paling sering dipakai dalam pengembangan sistem informasi dari tahun 2013-2018?

RQ2. Apa metode yang digunakan untuk menyelesaikan pengembangan sistem informasi tersebut?

RQ3. Apa kelemahan dari metode yang dipakai untuk menyelesaikan pengembangan sistem informasi tersebut?

3.2.2. Search Process. Search Process atau proses pencarian digunakan untuk mendapatkan sumbersumber yang relevan untuk menjawab Research Question (RQ) dan referensi terkait lainnya. Proses pencarian dilakukan dengan menggunakan search engine (Google Chrome) dengan alamat situs http://garuda.ristekdikti.go.id/ untuk data primer dan https://www.google.com untuk data sekunder.

3.2.3. Inclusion and Exclusion Criteria. Tahapan ini dilakukan untuk memutuskan apakah data yang ditemukan layak digunakan dalam penelitian SLR atau tidak. Studi layak dipilih jika terdapat kriteria sebagai berikut:

1. Data yang digunakan dalam rentang waktu 2013-2018.

2. Data diperoleh melalui situs http://garuda.ristekdikti.go.id/ dan https://www.google.com.

3. Data yang digunakan hanya berhubungan dengan sistem informasi.

3.2.4. Quality Assesment. Dalam penelitian SLR, data yang ditemukan akan dievaluasi berdasarkan pertanyaan kriteria penilaian kualitas sebagai berikut:

QA1. Apakah paper jurnal ditebitkan pada tahun 2013-2018?

QA2. Apakah pada paper jurnal menuliskan perangkat yang digunakan untuk pengembangan sistem informasi?

QA3. Apakah pada paper jurnal menuliskan metode yang digunakan untuk mengembangkan sistem informasi tersebut?

Dari masing-masing paper, akan diberi nilai jawaban di bawah ini untuk tiap-tiap pertanyaan di atas.

1. Y (Ya) : untuk masalah dan metode yang dituliskan pada paper jurnal dalam rentang waktu 2013-2018 dan,

2. T (Tidak) : untuk masalah dan metode yang tidak dituliskan.

3.2.5. Data Collection. Data Collection atau pengumpulan data adalah tahap di mana data-data untuk penelitian dikumpulkan. Data yang dikumpulkan dalam penelitian ini adalah data primer dan sekunder.

Triandini, Jayanatha, Indrawan, Putra, Iswara (Metode Systematic Literature Review untuk Identifikasi Platform dan Metode Pengembangan Sistem Informasi di Indonesia) 
3.2.5.1. Data Primer. Data primer adalah informasi yang dikumpulkan melalui survei, wawancara, observasi, dan disesuaikan dengan kebutuhan. Pada penelitian ini data primer yang diambil adalah jurnal-jurnal yang berasal dari http://garuda.ristekdikti.go.id/ dengan alasan sebagai berikut:

1. Garuda Ristekdikti memberikan fasilitas yang lengkap.

2. Data yang ditemukan mudah dicari, karena memiliki range tahun yang dapat disesuaikan berdasarkan kebutuhan peneliti.

3. Data yang ditampilkan dapat disesuaikan dengan kebutuhan.

3.2.5.2. Data Sekunder. Data sekunder digunakan untuk melengkapi data primer, apabila pada data primer hanya terdapat abstrak, maka diperlukan data sekunder untuk melengkapi data primer. Data sekunder diperoleh dengan menggunakan bantuan Google. Pengumpulan data dalam penelitian diperoleh melalui beberapa tahap, meliputi:

1. Observasi (Pengamatan)

Merupakan tahap pengumpulan data melalui pengamatan langsung ke sumber yaitu http://garuda.ristekdikti.go.id/.

2. Studi Pustaka

Merupakan tahap untuk melakukan studi pengkajian data terkait dengan Metode SLR pada jurnal yang diperoleh dari http://garuda.ristekdikti.go.id/.

3. Dokumentasi

Merupakan tahap di mana data yang telah dikumpulkan disimpan ke dalam perangkat lunak Mendeley.

Berikut langkah-langkah pengumpulan data mulai dari observasi hingga dokumentasi yang didapat melalui sumber http://garuda.ristekdikti.go.id/.

1. Mengunjungi situs http://garuda.ristekdikti.go.id/.

2. Memasukkan kata kunci "Sistem Informasi" pada form pencarian. Langkah ini dapat dilihat pada gambar 1.

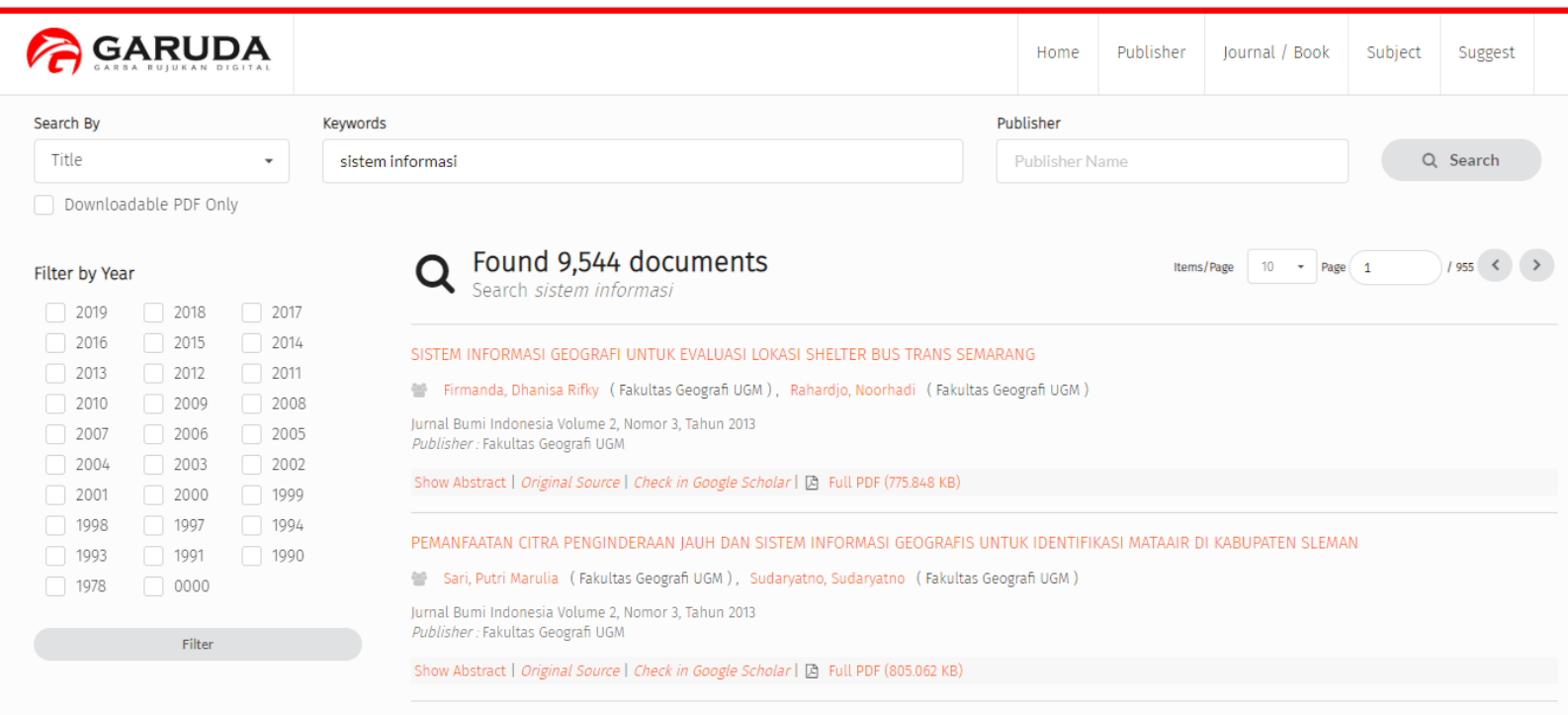

Gambar 1. Hasil pencarian kata kunci "Sistem Informasi"

3. Pada Filter by Year pilih Range, memilih tahun 2013-2018 untuk menentukan sumber tahun dalam menemukan isu sistem informasi. Setelah klik Filter, maka akan ditampilkan judul, tahun publikasi, dan nama penulis. Hasil yang ditampilkan oleh search process Garuda Ristekdikti adalah sebanyak 6807 jurnal seperti yang ditunjukkan pada gambar 2. 


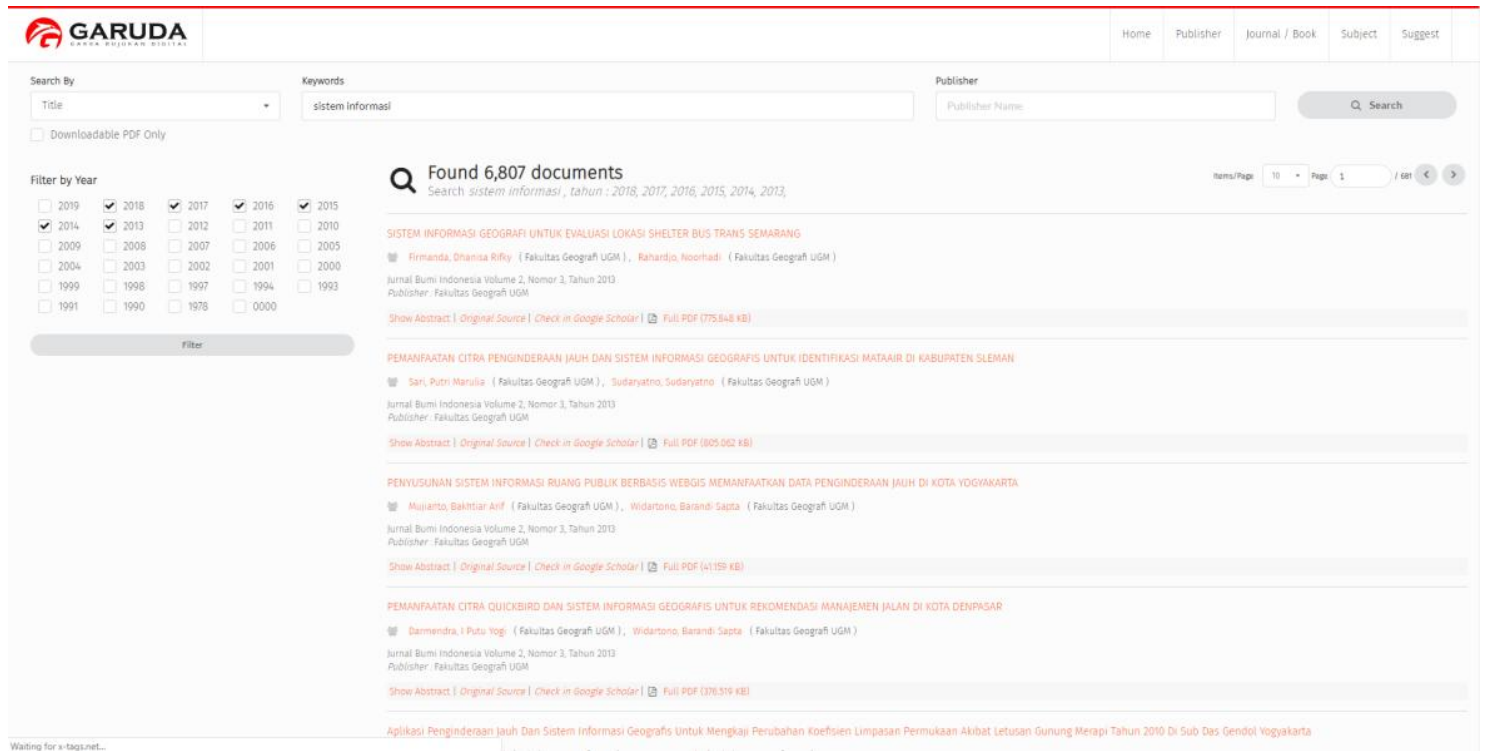

Gambar 2. Hasil pencarian jurnal pada Portal Garuda

3.2.6. Data Analysis. Pada tahap ini, data yang telah dikumpulkan akan dianalisa untuk menunjukkan:

1. Perangkat-perangkat yang digunakan dalam pengembangan sistem informasi dari tahun 20132018 (mengacu pada RQ1).

2. Metode/pendekatan yang digunakan dalam pengembangan sistem informasi (mengacu pada RQ2).

3. Kelemahan berbagai metode yang digunakan untuk pengembangan sistem informasi (mengacu pada RQ3).

3.2.7. Deviation from Protocol (Penyimpangan Laporan). Sebagai hasil dari kajian, penulis menuliskan beberapa perubahan pada deviation from protocol:

1. Penelitian ini mengidentifikasi platform dalam pengembangan sistem informasi di Indonesia, serta menjawab pertanyaan penelitian (Research Question).

2. Mengumpulkan jurnal untuk menjawab serta memastikan kualitas dan menyediakan informasi yang dibutuhkan.

3. Memperluas deskripsi tentang SLR pada penelitian ini.

\section{Hasil dan Pembahasan}

\subsection{Hasil Search Process}

Hasil search process yang ditampilkan pada tabel 1 dikelompokkan berdasarkan tipe jurnal untuk mempermudah melihat jenis data atau tipe jurnal yang diperoleh melalui search process.

Tabel 1. Pengelompokan berdasarkan Jurnal.

\begin{tabular}{llc}
\hline No. & \multicolumn{1}{c}{ Tipe Jurnal } & Jumlah \\
\hline 1 & $\begin{array}{l}\text { STUDIA INFORMATIKA: JURNAL SISTEM INFORMASI Vol 6, No 1 (2013): } \\
\text { Studia Informatika: Jurnal Sistem Informasi Vol.6 No. 1 Februari 2013 }\end{array}$ & 1 \\
2 & $\begin{array}{l}\text { Jurnal Optimasi Sistem Industri (JOSI): Media Ilmiah bagi Akademisi dan Praktisi } \\
\text { Industri Volume 12, No. 2, 2013 }\end{array}$ & 1 \\
3 & Jurnal Teknik ITS Vol 2, No 2 (2013) & 1 \\
4 & Jurnal Sarjana Teknik Informatika Vol 1, No 1 (2013) & 3 \\
5 & Jurnal Bumi Indonesia Volume 2, Nomor 3, Tahun 2013 & 4 \\
6 & Jurnal Bumi Indonesia Volume 2, Nomor 1, Tahun 2013 & 2 \\
7 & Jurnal Kesehatan Masyarakat (Journal of Public Health) Vol 7, No 1 (2013): Jurnal Kes & 1
\end{tabular}

Triandini, Jayanatha, Indrawan, Putra, Iswara (Metode Systematic Literature Review untuk Identifikasi Platform dan Metode Pengembangan Sistem Informasi di Indonesia) 
No.

Tipe Jurnal

Jumlah

Mas FKM UAD Januari 2013

8 Jurnal Kesehatan Masyarakat (Journal of Public Health) Vol 7, No 2 (2013): Jurnal Kes 1 Mas FKM UAD September 2013

9 Jurnal Informatika Vol 7, No 1: Januari 2013

10 JURNAL HUKUM UNSRAT Vol 21, No 4 (2013): JURNAL HUKUM UNSRAT

11 E-Jurnal Akuntansi Universitas Udayana Vol. 2, No. 1, Januari 2013

12 E-Jurnal Akuntansi Vol. 2, No.2, Februari 2013

13 Jurnal FKIP: REGION Vol 5, No 1 (2013): REGION

14 Jurnal Fakultas Teknik: RESULTAN Vol 13, No 2 (2013): RESULTAN 1

15 MEDIA GIZI MASYARAKAT INDONESIA Vol 2, No 2 (2013) 1

16 Jurnal Teknik Elektro Universitas Tanjungpura Vol 1, No 1 (2013): Jurnal Teknik 1 Elektro UNTAN

17 Jurnal Manajemen dan Bisnis Vol 1, No 1 (2013): Jurnal Manajemen dan Bisnis 1

18 STUDIA INFORMATIKA: JURNAL SISTEM INFORMASI Vol 6, No 1 (2013): 4 Studia Informatika: Jurnal Sistem Informasi Vol. 6 No. 1 Februari 2013

19 UG Journal Vol 7, No 5 (2013) 1

20 Jurnal Ilmiah Universitas Bakrie Vol 3, No 02 (2015): Mei 2015

21 Jurnal ITT Vol 1, No 1 (2013): Information Technology 1

22 Jurnal Teknik ITS Vol 2, No 2 (2013) 7

23 Jurnal Teknik ITS Vol 2, No 1 (2013) 2

24 REKA INTEGRA Vol 1, No 04 (2014): Edisi Keempat 2

25 REKA ELKOMIKA Vol 1, No 1 (2013) 1

26 Jurnal Teknik Industri USU Vol 1, No 2 (2013): Jurnal Teknik Industri USU 1

27 Jurnal Teknik Industri USU Vol 1, No 3 (2013): Jurnal Teknik Industri USU 1

28 Jurnal Ilmiah Universitas Bakrie Vol 1, No 02 (2013): Januari 2013

29 E-Jurnal Akuntasi Universitas Udayana VOL. 8, NO. 1, JULI 2014

30 Jurnal Intofel - Jurnal Informatika, Telekomunikasi dan Elektronika Vol 6, No 1 (2014): 1 Jurnal INTOFEL, Volume 6 Nomor 1 Mei 2014

31 IJNS - Indonesian Journal on Networking and Security Vol 3, No 3 (2014): IJNS Juli 1 2014

32 IJNS - Indonesian Journal on Networking and Security Vol 3, No 2 (2014): IJNS April 1 2014

33 Jurnal Geodesi Undip Volume 2, Nomor 1, Tahun 2013

34 2337-845X Volume 2, Nomor 2, Tahun $2013 \quad 5$

35 Jurnal Pendidikan Akuntansi (JPAK) Vol 1, No 1 (2013): 1

36 IJNS - Indonesian Journal on Networking and Security Vol 2, No 4 (2013): IJNS 4 Oktober 2013

37 IJNS - Indonesian Journal on Networking and Security IJNS - Accepted Paper 13

38 Journal of Politic and Government Studies Volume 2 Nomor 3 Tahun 2013

39 Jurnal Teknologi dan Sistem Komputer Volume 1, Nomor 1, Tahun 2013 (Januari 2013) 2

40 Jurnal Teknologi dan Sistem Komputer Volume 1, Nomor 2, Tahun 2013 (April 2013) 1

41 Jurnal Matematika JURNAL MATEMATIKA 2013

42 Jurnal Ekonomi, Bisnis \& Entrepreneurship Vol 10, No 1 (2016): Jurnal Ekonomi, 1

Triandini, Jayanatha, Indrawan, Putra, Iswara (Metode Systematic Literature Review untuk Identifikasi Platform dan Metode Pengembangan Sistem Informasi di Indonesia) 


\begin{tabular}{|c|c|c|}
\hline No. & Tipe Jurnal & Jumlah \\
\hline & Bisnis \& Entrepreneurship & \\
\hline 43 & SISFO Vol 6 No 2 (2017) & 4 \\
\hline 44 & SISFO Vol 7 No 1 (2017) & 1 \\
\hline 45 & Jurnal Ketahanan Nasional Vol 23, No 2 (2017) & 1 \\
\hline 46 & $\begin{array}{l}\text { JSM (Jurnal SIFO Mikroskil) Vol 16, No } 1 \text { (2016): JSM Volume } 16 \text { Nomor } 1 \text { Tahun } \\
2015\end{array}$ & 1 \\
\hline 47 & Jurnal Ilmiah Mahasiswa FEB Vol 6, No 1 : Semester Ganjil 2017/2018 & 1 \\
\hline 48 & Network Engineering Research Operation [NERO] Vol 2, No 2 (2016): Nero & 1 \\
\hline 49 & $\begin{array}{l}\text { INFORMATICS FOR EDUCATORS AND PROFESSIONALS Vol } 1 \text { No } 1 \text { (2016): } \\
\text { Informatics For Educators And Professionals }\end{array}$ & 1 \\
\hline 50 & Journal of Public Policy and Management Review Vol 5, No 1 (2016): JANUARI 2016 & 1 \\
\hline 51 & Jurnal Administrasi Publik Vol 4, No 2 (2016) & 1 \\
\hline 52 & Jurnal Administrasi Publik Vol 4, No 3 (2016) & 1 \\
\hline 53 & $\begin{array}{l}\text { Jurnal Ilmiah Mahasiswa Ekonomi Akuntansi Vol 2, No } 4 \text { (2017): Jurnal Ilmiah } \\
\text { Mahasiswa Ekonomi Akuntansi }\end{array}$ & 1 \\
\hline 54 & Jurnal Informatika Vol 10, No 1 (2016): Januari & 2 \\
\hline 55 & $\begin{array}{l}\text { Speed - Sentra Penelitian Engineering dan Edukasi Vol 8, No } 1 \text { (2016): Jurnal Speed } 29 \\
-2016\end{array}$ & 4 \\
\hline 56 & $\begin{array}{l}\text { IJNS - Indonesian Journal on Networking and Security 2016: IJNS Februari } 2016 \\
\text { Accepted Paper }\end{array}$ & 4 \\
\hline 57 & IJSE - Indonesian Journal on Software Engineering 2016: IJSE Accepted Paper & 1 \\
\hline 58 & Fakultas Ilmu Sosial dan Ilmu Politik Vol 5, No 1 (2016) & 1 \\
\hline 59 & MATICS Vol 10, No 1 (2018): MATICS & 1 \\
\hline 60 & SISFO Vol 8 No 1 (2018) & 1 \\
\hline 61 & SISFO Vol 7 No 2 (2018) & 1 \\
\hline \multirow[t]{2}{*}{62} & SISFO Vol 7 No 3 (2018) & 1 \\
\hline & Total & 111 \\
\hline
\end{tabular}

\subsection{Hasil Seleksi Inclusion and Exclusion Criteria}

Hasil dari search process akan diseleksi berdasarkan kriteria batasan dan pemasukan (inclusion and exclusion criteria). Proses ini menyisakan 44 jurnal dan selanjutnya dilakukan scanning data. Tabel 2 menunjukkan hasil kualitas penilaian untuk yang memperlihatkan apakah data tersebut digunakan atau tidak dalam penelitian ini.

\subsection{Hasil Kualitas Penilaian (Quality Assesment)}

Tabel 2. Hasil Kualitas Penilaian (Quality Assesment)

\begin{tabular}{|c|c|c|c|c|c|c|c|}
\hline No. & Penulis & Judul & Tahun & QA1 & QA2 & QA3 & Hasil \\
\hline 1 & $\begin{array}{l}\text { Yudi Fahrozi, Nur } \\
\text { Aeni Hidayah, } \\
\text { Nia Kumaladewi }\end{array}$ & $\begin{array}{lcr}\text { Pengembangan } & \text { Sistem } & \text { Informasi } \\
\text { Peminjaman } & \text { Berkas } & \text { Putusan } \\
\text { Pengadilan Pajak pada } & \text { Sekretariat } \\
\text { Pengadilan Pajak } & & \end{array}$ & 2013 & $\mathrm{Y}$ & $\mathrm{Y}$ & $\mathrm{Y}$ & $\checkmark$ \\
\hline 2 & $\begin{array}{l}\text { Lasmedi Afuan, } \\
\text { Ipung Permadi }\end{array}$ & $\begin{array}{l}\text { Rancang Bangun Sistem Informasi } \\
\text { Laboratorium (Silab) Berbasis Web } \\
\text { di Teknik Informatika Unsoed }\end{array}$ & 2013 & Y & Y & $\mathrm{Y}$ & $\checkmark$ \\
\hline 3 & $\begin{array}{l}\text { Dina Rahmayanti, } \\
\text { Ringgo Afrinando }\end{array}$ & $\begin{array}{l}\text { Perancangan Sistem Informasi pada } \\
\text { Bagian Gudang PT. PN VI Unit }\end{array}$ & 2013 & Y & $\mathrm{Y}$ & Y & $\checkmark$ \\
\hline
\end{tabular}

Triandini, Jayanatha, Indrawan, Putra, Iswara (Metode Systematic Literature Review untuk Identifikasi Platform dan Metode Pengembangan Sistem Informasi di Indonesia) 


\begin{tabular}{|c|c|c|c|c|c|c|c|}
\hline No. & Penulis & Judul & Tahun & QA1 & QA2 & QA3 & Hasil \\
\hline 4 & $\begin{array}{l}\text { Ignatius Pricher } \\
\text { Agung Nirwanto } \\
\text { Samane }\end{array}$ & $\begin{array}{l}\text { Usaha Ophir } \\
\text { Pengembangan Sistem Informasi } \\
\text { Rayonisasi Wilayah Penjualan } \\
\text { dengan Metode Time and Territory } \\
\text { Management Studi Kasus di PT. } \\
\text { Sinar Intermark Cabang Yogyakarta }\end{array}$ & 2013 & Y & Y & Y & $\checkmark$ \\
\hline 5 & $\begin{array}{l}\text { Arif Setiyanto, } \\
\text { Febriliyan } \\
\text { Samopa dan Alwi }\end{array}$ & $\begin{array}{lll}\text { Pembuatan } & \text { Sistem Informasi Cuti } \\
\text { pada Kantor } & \text { Pelayanan } \\
\text { Perbendaharaan Negara dengan } \\
\text { Menggunakan PHP dan MySQL }\end{array}$ & 2013 & Y & Y & Y & $\checkmark$ \\
\hline 6 & $\begin{array}{l}\text { T.Indra Wardana, } \\
\text { Eko Aribowo }\end{array}$ & $\begin{array}{l}\text { Perancangan dan Implementasi } \\
\text { Sistem Informasi Manajemen } \\
\text { Kegiatan Masjid Studi Kasus: Masjid } \\
\text { Jogokariyan Yogyakarta }\end{array}$ & 2013 & Y & Y & Y & $\checkmark$ \\
\hline 7 & Tedy Setiadi & $\begin{array}{l}\text { Perancangan Sistem Informasi } \\
\text { Geografis Pemetaan Daerah Rawan } \\
\text { Tanah Longsor, Mitigasi dan } \\
\text { Manajemen Bencana Di Kabupaten } \\
\text { Banjarnegara }\end{array}$ & 2013 & Y & Y & Y & $\checkmark$ \\
\hline 8 & $\begin{array}{l}\text { Arie } \\
\text { Saputra }\end{array}$ & $\begin{array}{l}\text { Perancangan Sistem Informasi } \\
\text { Penggajian Pada Sekolah Menengah } \\
\text { Pertama (SMP) PGRI Kebonagung }\end{array}$ & 2014 & Y & Y & Y & $\checkmark$ \\
\hline 9 & $\begin{array}{l}\text { M. Insya } \\
\text { Dzulkarnain, } \\
\text { Rispianda, } \\
\text { Cahyadi Nugraha }\end{array}$ & $\begin{array}{l}\text { Sistem Informasi Rekam Jejak } \\
\text { Proses Produksi Serat Rayon di Pt. } \\
\text { Indo-Bharat Rayon }\end{array}$ & 2014 & Y & Y & Y & $\checkmark$ \\
\hline 10 & $\begin{array}{l}\text { Ana Husnul } \\
\text { Khotimah, Siska } \\
\text { Iriani }\end{array}$ & $\begin{array}{l}\text { Sistem Informasi Nilai Siswa pada } \\
\text { Madrasah Tsanawiyah (Mts) Al } \\
\text { Muhajirin Kalak Donorojo }\end{array}$ & 2014 & Y & Y & Y & $\checkmark$ \\
\hline 11 & $\begin{array}{l}\text { Siska Iriani, M. } \\
\text { Suyanto, } \\
\text { Armadyah } \\
\text { Amborowati }\end{array}$ & $\begin{array}{lrr}\text { Pengujian Sistem Informasi } \\
\text { Pengelolaan Keuangan } & \text { Daerah } \\
\text { Berbasis Web Kabupaten } & \text { Pacitan } \\
\text { dengan Menggunakan Unified Theory } \\
\text { of Acceptance and Use of Technology } \\
\text { (UTAUT) }\end{array}$ & 2014 & Y & Y & $\mathrm{Y}$ & $\checkmark$ \\
\hline 12 & $\begin{array}{ll}\text { I Putu } & \text { Yogi } \\
\text { Darmendra }\end{array}$ & $\begin{array}{l}\text { Pemanfaatan Citra Quickbird dan } \\
\text { Sistem Informasi Geografis untuk } \\
\text { Rekomendasi Manajemen Jalan di } \\
\text { Kota Denpasar }\end{array}$ & 2013 & Y & $\mathrm{X}$ & Y & $\checkmark$ \\
\hline 13 & $\begin{array}{l}\text { Carwoto, } \\
\text { Bambang } \\
\text { Wijayanto }\end{array}$ & $\begin{array}{l}\text { Pengembangan dan Implementasi } \\
\text { Sistem Informasi Jejaring Rujukan } \\
\text { Kegawatdaruratan Maternal-Neonatal } \\
\text { Berbasis Web dan SMS (Short } \\
\text { Message Service) }\end{array}$ & 2013 & $\mathrm{Y}$ & Y & Y & $\checkmark$ \\
\hline 14 & $\begin{array}{l}\text { Noval Aditya } \\
\text { Muhammad, } \\
\text { Febriliyan } \\
\text { Samopa dan } \\
\text { Radityo } \\
\text { Prasetianto } \\
\text { Wibowo }\end{array}$ & 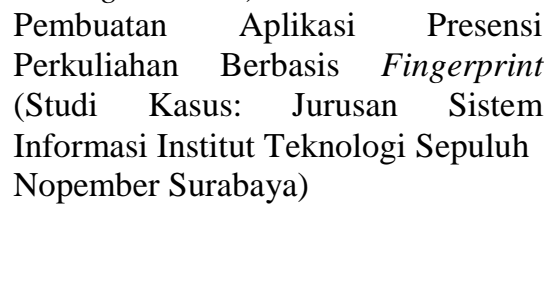 & 2013 & Y & Y & Y & $\checkmark$ \\
\hline 15 & $\begin{array}{l}\text { Ni Made Ayu } \\
\text { Marlinawati, } \\
\text { I.G.N Agung } \\
\text { Suaryana }\end{array}$ & 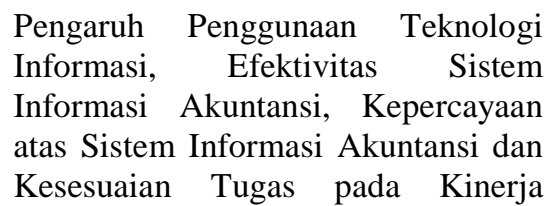 & 2013 & Y & $\mathrm{X}$ & X & $X$ \\
\hline
\end{tabular}




\begin{tabular}{|c|c|c|c|c|c|c|c|}
\hline No. & Penulis & Judul & Tahun & QA1 & QA2 & QA3 & Hasil \\
\hline 16 & Carlo A.Gerungan & $\begin{array}{l}\text { Karyawan Lembaga Perkreditan Desa } \\
\text { di Kabupaten Badung } \\
\text { Tanggung Jawab } \\
\text { Sistem Informasi } \\
\text { Kengelenggara } \\
\text { Kegagalan Sistem }\end{array}$ & 2013 & Y & $\mathrm{X}$ & $\mathrm{Y}$ & $\checkmark$ \\
\hline 17 & $\begin{array}{ll}\text { Murniati, } & \text { Nia } \\
\text { Kumaladewi } & \text { dan } \\
\text { Zulfiandri } & \end{array}$ & $\begin{array}{ll}\text { Pengembangan } & \text { Sistem Informasi } \\
\text { Penjualan pada } & \text { PD. Hikmah Jaya } \\
\text { Jakarta Barat } & \end{array}$ & 2013 & Y & Y & Y & $\checkmark$ \\
\hline 18 & $\begin{array}{lr}\text { Candra } & \text { Dwi } \\
\text { Aprida } & \text { dan } \\
\text { Febriliyan } & \\
\text { Samopa } & \end{array}$ & $\begin{array}{l}\text { Pembuatan Sistem Informasi } \\
\text { Beasiswa Internal Direktorat Jenderal } \\
\text { Perbendaharaan Menggunakan PHP } \\
\text { dan MySQL }\end{array}$ & 2013 & Y & Y & $\mathrm{y}$ & $\checkmark$ \\
\hline 19 & $\begin{array}{l}\text { Ainnur Rofiq, } \\
\text { Sholiq, dan Feby } \\
\text { Artwodini } \\
\text { Muqtadiroh }\end{array}$ & $\begin{array}{l}\text { Rancang Bangun Aplikasi Sistem } \\
\text { Informasi Manajemen Pelatihan } \\
\text { (SIMPEL) pada Lembaga Pelatihan } \\
\text { XYZ }\end{array}$ & 2013 & $\mathrm{Y}$ & Y & $\mathrm{Y}$ & $\checkmark$ \\
\hline 20 & $\begin{array}{lr}\text { Jessica } & \text { Novia, } \\
\text { Humala } & \text { L. } \\
\text { Napitupulu, } \\
\text { Mangara } \\
\text { Tambunan }\end{array}$ & 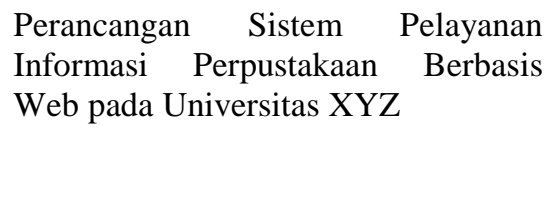 & 2013 & Y & Y & Y & $\checkmark$ \\
\hline 21 & $\begin{array}{l}\text { William, Humala } \\
\text { L. Napitupulu, } \\
\text { Aulia Ishak }\end{array}$ & $\begin{array}{l}\text { Rancangan Sistem Informasi } \\
\text { Perawatan Mesin pada Pabrik Crumb } \\
\text { Rubber PT. HB }\end{array}$ & 2013 & Y & Y & Y & $\checkmark$ \\
\hline 22 & $\begin{array}{l}\text { Susy Kusuma } \\
\text { Wardani }\end{array}$ & $\begin{array}{l}\text { Sistem Informasi Pengolahan Data } \\
\text { Nilai Siswa Berbasis Web pada } \\
\text { Sekolah Menengah Kejuruan (SMK) } \\
\text { PGRI } 1 \text { Pacitan }\end{array}$ & 2013 & Y & Y & Y & $\checkmark$ \\
\hline 23 & $\begin{array}{l}\text { Erni Irawati, } \\
\text { Siska Iriani }\end{array}$ & $\begin{array}{l}\text { Sistem Informasi Penjualan Bahan } \\
\text { Pertanian pada Unit Dagang (UD) } \\
\text { Mitra Tani }\end{array}$ & 2013 & Y & Y & Y & $\checkmark$ \\
\hline 24 & $\begin{array}{l}\text { Nuzuliarini Nuris, } \\
\text { Eka Rini Yulia }\end{array}$ & $\begin{array}{l}\text { Rancang Bangun Sistem Informasi } \\
\text { Pelayanan Tamu pada Hotel Rensa } \\
\text { Jakarta }\end{array}$ & 2018 & Y & Y & $\mathrm{Y}$ & $\checkmark$ \\
\hline 25 & $\begin{array}{l}\text { Faisal Akmal, } \\
\text { Fatwa Ramdani, } \\
\text { Aryo Pinandito }\end{array}$ & $\begin{array}{l}\text { Sistem Informasi } \begin{array}{r}\text { Pengelolaan } \\
\text { Perkebunan Kelapa } \\
\text { Web GIS }\end{array}\end{array}$ & 2018 & $\mathrm{Y}$ & Y & Y & $\checkmark$ \\
\hline 26 & $\begin{array}{l}\text { Mohammad } \\
\text { Mirza Zanuar, } \\
\text { Mochammad } \\
\text { Chandra Saputra, } \\
\text { Fajar Pradana }\end{array}$ & $\begin{array}{lrr}\text { Pengembangan } & \text { Sistem } & \text { Informasi } \\
\text { KIM (Kelompok } & \text { Informasi } \\
\text { Masyarakat) } & \text { KOMINFO } & \text { Jatim } \\
\text { Berbasis Web } & & \\
\end{array}$ & 2018 & Y & Y & $\mathrm{Y}$ & $\checkmark$ \\
\hline 27 & $\begin{array}{l}\text { Arel Riedsa } \\
\text { Adiguna, } \\
\text { Mochamad } \\
\text { Chandra Saputra, } \\
\text { Fajar Pradana }\end{array}$ & $\begin{array}{l}\text { Analisis dan Perancangan Sistem } \\
\text { Informasi Manajemen Gudang pada } \\
\text { PT Mitra Pinasthika Mulia Surabaya }\end{array}$ & 2018 & Y & $\mathrm{X}$ & Y & $\checkmark$ \\
\hline 28 & $\begin{array}{l}\text { Hidayatullah } \\
\text { Agung Prasetyo, } \\
\text { Bayu } \\
\text { Priyambadha, } \\
\text { Achmad Arwan }\end{array}$ & $\begin{array}{l}\text { Pembangunan Aplikasi Sistem } \\
\text { Informasi Pergudangan pada Rumah } \\
\text { Sakit Umum Daerah Dr. Murjani } \\
\text { Sampit Kabupaten Kotawaringin } \\
\text { Timur }\end{array}$ & 2018 & $\mathrm{Y}$ & Y & $\mathrm{Y}$ & $\checkmark$ \\
\hline 29 & Suhendri & $\begin{array}{lcrr}\text { Rancang } & \text { Bangun } & \text { Sistem Informasi } \\
\text { Geografis } & \text { untuk Pemetaan } & \text { dan } \\
\text { Informasi } & \text { Kondisi } & \text { Hutan } & \text { di } \\
\text { Kabupaten Majalengka } & & \end{array}$ & 2017 & $\mathrm{Y}$ & $\mathrm{Y}$ & $\mathrm{Y}$ & $\checkmark$ \\
\hline
\end{tabular}




\begin{tabular}{|c|c|c|c|c|c|c|c|}
\hline No. & Penulis & Judul & Tahun & QA1 & QA2 & QA3 & Hasil \\
\hline 30 & Ali Mustopa & $\begin{array}{l}\text { Sistem Informasi IT-Helpdesk Pada } \\
\text { Universitas Amikom Yogyakarta } \\
\text { Berbasis Web }\end{array}$ & 2017 & $\mathrm{Y}$ & $\mathrm{Y}$ & $\mathrm{Y}$ & $\checkmark$ \\
\hline 31 & $\begin{array}{l}\text { Yana } \\
\text { Maulana }\end{array}$ & $\begin{array}{l}\text { Perancangan Perangkat Lunak Sistem } \\
\text { Informasi Pendataan Guru dan } \\
\text { Sekolah (SINDARU) pada Dinas } \\
\text { Pendidikan Kota Tangerang Selatan }\end{array}$ & 2017 & $\mathrm{Y}$ & Y & $\mathrm{Y}$ & $\checkmark$ \\
\hline 32 & $\begin{array}{l}\text { Halimah, Dian } \\
\text { Kinanti }\end{array}$ & $\begin{array}{l}\text { E-Customer } \\
\text { Management (CRM) untuk Sistem } \\
\text { Informasi Paket Wisata pada CV. } \\
\text { Alea Tour \& Travel Bandar Lampung }\end{array}$ & 2017 & $\mathrm{Y}$ & $\mathrm{Y}$ & $\mathrm{Y}$ & $\checkmark$ \\
\hline 33 & Marini & $\begin{array}{l}\text { Rancang Bangun Sistem Informasi } \\
\text { Kenaikan Pangkat Pegawai pada } \\
\text { Kantor Kecamatan Bukit Intan }\end{array}$ & 2017 & $Y$ & Y & $\mathrm{Y}$ & $\checkmark$ \\
\hline 34 & $\begin{array}{l}\text { Andri } \\
\text { Gunawan } \\
\text { Abdillah, } \\
\text { Renaldi }\end{array}$ & $\begin{array}{l}\text { Sistem Informasi Terintegrasi pada } \\
\text { Proses Pendaftaran dan Menabung di } \\
\text { Bank Sampah Induk Cimahi Berbasis } \\
\text { Mobile }\end{array}$ & 2016 & $\mathrm{Y}$ & Y & Y & $\checkmark$ \\
\hline 35 & $\begin{array}{l}\text { Rozzi } \quad \text { Kesuma } \\
\text { Dinata }\end{array}$ & $\begin{array}{l}\text { Sistem Informasi Pendataan } \\
\text { Mahasiswa Kerja Praktek di Bank } \\
\text { BRI Unit Cot Girek Kanca } \\
\text { Lhokseumawe }\end{array}$ & 2016 & Y & Y & Y & $\checkmark$ \\
\hline 36 & $\begin{array}{l}\text { Asmoro Bangun } \\
\text { Priambodo, } \\
\text { Herlawati }\end{array}$ & $\begin{array}{l}\text { Sistem Informasi Ujian Berbasis Web } \\
\text { Pada SD Islam Teratai Putih Global } \\
\text { Bekasi }\end{array}$ & 2016 & Y & Y & $\mathrm{Y}$ & $\checkmark$ \\
\hline 37 & $\begin{array}{l}\text { Endang } \\
\text { Retnoningsih }\end{array}$ & $\begin{array}{l}\text { Sistem Informasi Simpanan dan } \\
\text { Pembiayaan pada Baitul Maal Wat } \\
\text { Tamwil (BMT) Al-Multazam } \\
\text { Kabupaten Tegal }\end{array}$ & 2015 & Y & Y & Y & $\checkmark$ \\
\hline 38 & $\begin{array}{l}\text { Bahryan } \\
\text { Purmadipta, } \\
\text { Hengky Anra, M. } \\
\text { Azhar Irwansyah. }\end{array}$ & $\begin{array}{l}\text { Sistem Informasi Geografis } \\
\text { Perumahan dan Fasilitas Sosial } \\
\text { Terdekat dengan Metode Haversine } \\
\text { Formula }\end{array}$ & 2016 & Y & Y & $\mathrm{Y}$ & $\checkmark$ \\
\hline 39 & $\begin{array}{l}\text { Suraya, } \quad \text { M. } \\
\text { Andang Novianta }\end{array}$ & $\begin{array}{l}\text { Sistem Informasi Database Multi- } \\
\text { Node Pemantauan Pergeseran Tanah } \\
\text { Berbasis Sms Gateway dan }\end{array}$ & 2016 & Y & $\mathrm{T}$ & $\mathrm{T}$ & $\checkmark$ \\
\hline 40 & $\begin{array}{ll}\text { Eka Mala } & \text { Sari } \\
\text { Rochman, } & \text { Aeri } \\
\text { Rachmad } & \end{array}$ & $\begin{array}{l}\text { Berorientasi Visual pada Komputer } \\
\text { Sistem Informasi Anggaran Belanja }\end{array}$ & 2016 & Y & Y & $\mathrm{Y}$ & $\checkmark$ \\
\hline 41 & $\begin{array}{l}\text { Meryline Pinlisa } \\
\text {.Surbakti, Anggi } \\
\text { Srimurdianti, } \\
\text { Yulianti }\end{array}$ & $\begin{array}{l}\text { Rancang Bangun Sistem Informasi } \\
\text { Manajemen Produk CV. Mitra } \\
\text { Surbakti (Studi Kasus: CV. Mitra } \\
\text { Surbakti Pontianak) }\end{array}$ & 2016 & Y & Y & $\mathrm{Y}$ & $\checkmark$ \\
\hline 42 & $\begin{array}{lr}\text { Fandi } & \text { Halim, } \\
\text { Gunawan, } & \text { Indra } \\
\text { Prasetya, } & \text { Iga } \\
\text { Mentari } & \end{array}$ & $\begin{array}{l}\text { Pengembangan Sistem Informasi } \\
\text { Pengelolaan Proyek pada CV. Tricore } \\
\text { Media Teknologi }\end{array}$ & 2015 & $\mathrm{Y}$ & $\mathrm{Y}$ & $\mathrm{Y}$ & $\checkmark$ \\
\hline 43 & $\begin{array}{l}\text { Bambang Agus } \\
\text { Herlambang, } \\
\text { Vilda Ana Veria } \\
\text { Setyawati }\end{array}$ & $\begin{array}{l}\text { Desain Sistem Informasi Geografis } \\
\text { Pemetaan Gizi Buruk di Kota } \\
\text { Semarang }\end{array}$ & 2016 & Y & Y & Y & $\checkmark$ \\
\hline 44 & $\begin{array}{l}\text { Maharani, Septya, } \\
\text { Harsa K, Awang, } \\
\text { Nalarwati, Atik } \\
\text { Tia }\end{array}$ & $\begin{array}{l}\text { Sistem Informasi Geografi (SIG) } \\
\text { Pencarian ATM Bank Kaltim } \\
\text { Terdekat dengan Geolocation dan } \\
\text { Haversine Formula Berbasis Web }\end{array}$ & 2017 & $\mathrm{Y}$ & $\mathrm{Y}$ & $\mathrm{Y}$ & $\checkmark$ \\
\hline
\end{tabular}




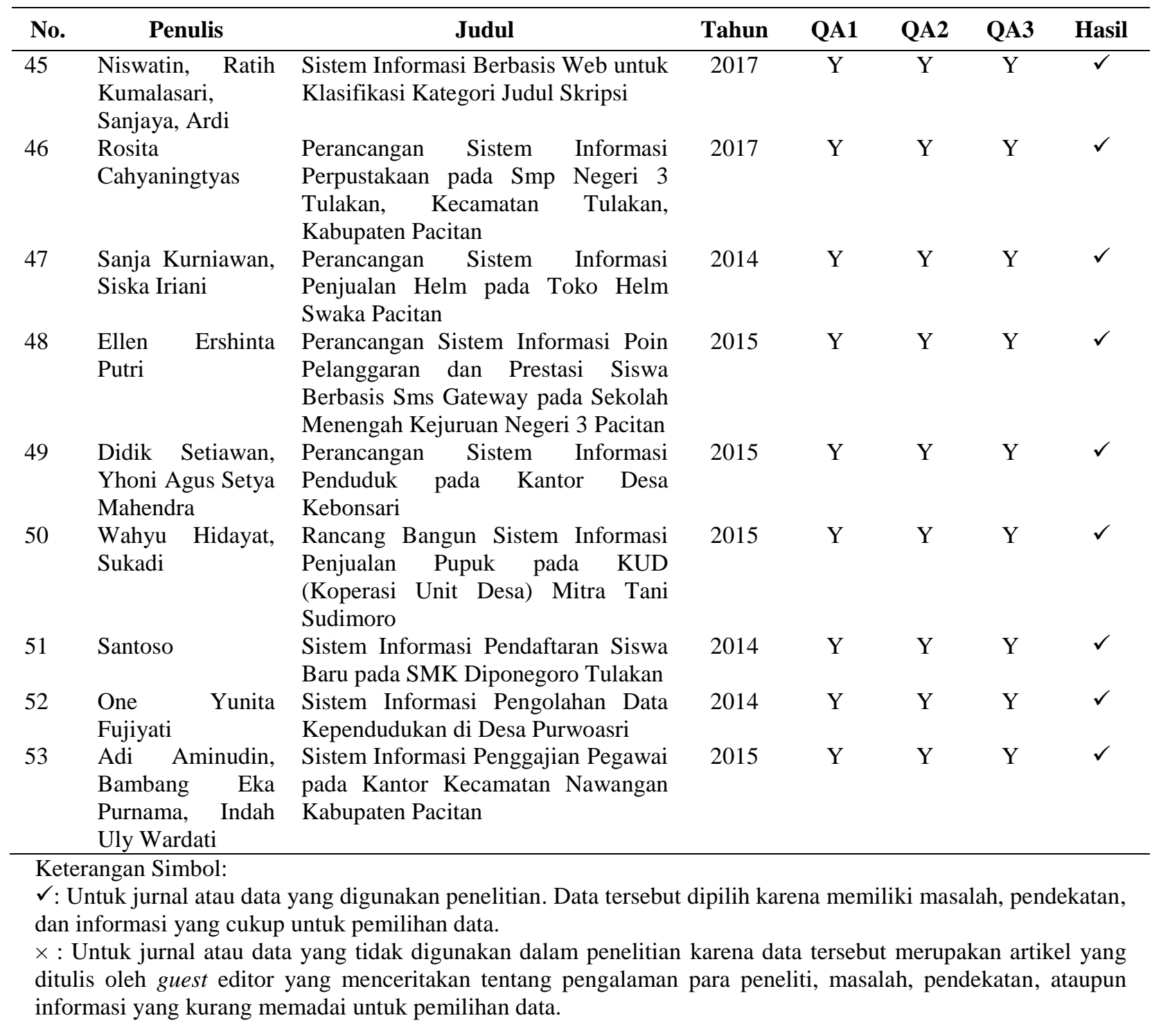

\subsection{Analisis Data (Data Analysis)}

Tahapan ini akan menjawab pertanyaan dari Research Question (RQ) dan membahas hasil dari metode serta pendekatan yang dominan muncul dari tahun 2013-2018.

\subsubsection{Pembahasan Hasil. Bagian ini akan menjelaskan/menjawab Research Question (RQ).}

\section{RQ1. Apa perangkat paling sering digunakan dalam pengembangan sistem informasi dari tahun 2013-2018?}

Secara keseluruhan terdapat 111 jurnal melalui search process. Setelah data diseleksi berdasarkan inclusion and exclusion criteria dengan menggunakan kata kunci (keyword) "sistem informasi" terdapat 53 artikel jurnal yang kemudian diberi kualitas penilaian (Quality Assesment). Dari hasil Quality Assessment (QA) terdapat 52 artikel jurnal yang relevan yang kemudian dikelompokkan berdasarkan platform pengembangan dan pendekatan yang digunakan untuk menjawab research question. Hasil ini menjawab RQ1, yang ditampilkan pada tabel 3. Tabel 3 menunjukkan bahwa platform yang dominan digunakan dalam pengembangan sistem informasi adalah Web-Based/website. 
Tabel 3. Pengelompokan Platform

\begin{tabular}{llc}
\hline No. & Platform & Jumlah \\
\hline 1 & Web Based & 33 \\
2 & Desktop & 14 \\
3 & Mobile Application & 0 \\
\hline
\end{tabular}

5.4.2. Website. Situs web adalah kumpulan halaman web yang saling terhubung dan file-filenya saling terkait. Web terdiri dari page atau halaman dan kumpulan halaman yang dinamakan homepage. Homepage berada pada posisi teratas, dengan halaman-halaman terkait berada di bawahnya. Informasi dalam web berbentuk digital baik itu teks, gambar, animasi yang disediakan melalui jalur internet. Hal ini membuat web dapat diakses dari seluruh dunia asalkan memiliki koneksi internet. Berdasarkan sifatnya, suatu website dibagi menjadi 2 jenis, yaitu:

5.4.2.1. Website Statis.Web yang halamannya tidak berubah, biasanya untuk melakukan perubahan dilakukan secara manual dengan mengubah kode. Website statis memiliki informasi yang bersifat satu arah, yakni hanya berasal dari pemilik softwarenya saja dan hanya bisa diupdate oleh pemiliknya. Salah satu contoh website statis adalah profil perusahaan.

5.4.2.2. Website Dinamis. Merupakan web dengan halaman yang selalu update. Biasanya terdapat halaman backend (halaman administrator) yang digunakan untuk menambah atau mengubah konten. Web dinamis membutuhkan database untuk menyimpan. Website dinamis mempunyai arus informasi dua arah, yakni berasal dari pengguna dan pemilik, sehingga update dapat dilakukan oleh pengguna dan juga pemilik website [11]. Terdapat beberapa unsur-unsur pembangun website atau situs agar dapat berjalan dengan baik. Unsur-unsur tersebut meliputi:

1. Domain Name

Unsur pertama adalah nama domain yakni alamat permanen situs di dunia internet untuk mengidentifikasi situs atau dengan kata lain alamat yang digunakan untuk menemukan situs pada dunia internet. Istilah umum yang digunakan adalah URL (Uniform Resource Locator). Nama domain dari tiap-tiap situs di seluruh dunia tidak ada yang sama sehingga tidak ada satu pun situs yang akan dijumpai tertukar nama atau tertukar halaman situsnya. Untuk memperoleh nama dilakukan penyewaan domain, biasanya dalam jangka tertentu (tahunan).

2. Hosting

Hosting dapat diartikan sebagai ruangan yang terdapat dalam harddisk tempat menyimpan berbagai data, file-file, gambar, dan lain sebagainya yang akan ditampilkan di situs. Besarnya data yang bisa dimasukkan tergantung besarnya hosting yang disewa atau dipunyai, semakin besar hosting semakin besar pula data yang dapat dimasukkan dalam situs. Besarnya hosting ditentukan ruangan hardisk dengan ukuran MB (Mega Byte) atau GB (Giga Byte). Lama penyewaan hosting rata-rata dihitung per tahun. Penyewaan hosting dilakukan dari perusahaanperusahaan penyewa web hosting yang banyak dijumpai baik di Indonesia maupun luar negeri.

3. Scripts (Bahasa Program)

Scripts adalah bahasa yang digunakan untuk menerjemahkan tiap perintah dalam situs ketika diakses. Jenis scripts sangat menentukan statis, dinamis atau interaktifnya sebuah situs. Semakin banyak ragam scripts yang digunakan maka akan terlihat situs semakin dinamis, dan interaktif serta terlihat bagus. Jenis-jenis scripts yang banyak dipakai antara lain HTML (HyperText Markup Language), ASP (Active Server Pages), PHP (Hypertext Preprocessor), JSP (Java Server Page), Java Scripts, Java applets dan sebagainya. Bahasa dasar yang dipakai setiap situs adalah HTML sedangkan ASP dan lainnya merupakan bahasa pendukung yang mengatur dinamis dan interaktifnya situs.

4. Desain Web

Desain web sangat menentukan kualitas dan keindahan dan sangat berpengaruh kepada penilaian pengunjung akan bagus tidaknya sebuah website. Pesatnya perkembangan dan 
integrasi teknologi kini telah membuat desain website yang ada semakin menarik dan canggih [12].

5. Publikasi

Keberadaan situs tidak ada gunanya dibangun tanpa dikunjungi atau dikenal oleh masyarakat atau pengunjung internet. Publikasi, promosi dan iklan diperlukan untuk mengenalkan situs kepada target customer [13]. Publikasi situs dapat dilakukan dengan cara offline (seperti pamflet, selebaran, baliho dan lain-lain) tapi cara ini bisa dikatakan masih kurang efektif dan sangat terbatas. Cara yang paling efektif dan tak terbatas ruang atau waktu adalah publikasi langsung secara online melalui search engine (seperti: Yahoo, Google, Search Indonesia, dan sebagainya).

RQ2. Apa metode yang sering digunakan untuk menyelesaikan pengembangan sistem informasi tersebut?

Tabel 4 menampilkan hasil pengelompokan metode yang menjawab RQ2. Berdasarkan tabel 4 metode yang dominan dalam pengembangan sistem informasi (2013-2018) adalah metode terstruktur.

Tabel 4. Pengelompokan Pendekatan (Metode)

\begin{tabular}{lll}
\hline No. & Platform & Jumlah \\
\hline 1 & Metode Terstruktur & 30 \\
2 & Metode Object Oriented & 14 \\
\hline
\end{tabular}

5.4.3. Metode Terstruktur. Metode terstruktur dalam pengembangan sistem informasi atau yang lebih dikenal dengan System Development Life Cycle (SDLC) meningkatkan kontrol pengelolaan dengan membagi tugas kompleks menjadi bagian-bagian kecil yang lebih mudah dikelola [14]. Tahapantahapan dalam SDLC antara lain sebagai berikut:

\section{Planning}

Tahapan ini adalah tahap untuk mendefinisikan masalah dan menentukan tujuan kegiatan yang menyangkut estimasi dari kebutuhan-kebutuhan fisik, tenaga kerja, dan dana yang dibutuhkan untuk mendukung pengembangan sistem serta mendukung operasionalnya setelah diterapkan.

2. Analysis

Tahapan ini adalah tahapan untuk mengidentifikasi masalah dan mencari solusinya. Biasanya dibuat flowchart untuk mengidentifikasi.

3. Design

Tahapan ini adalah tahap perancangan sistem kegiatan yang dilakukan yaitu membuat pemodelan proses, membuat pemodelan data berupa DFD (Data Flow Diagram) dan membuat desain tampilan antarmuka (interface).

4. Development

Tahapan ini adalah tahap pembuatan technical architecture dan database. Mengkonversikan perancangan logikal ke dalam kode dengan menggunakan bahasa pemrograman tertentu.

5. Testing

Dalam tahap ini tidak hanya menguji desain yang digunakan namun menguji semua sistem yang telah ditetapkan, seperti tidak ada kesalahan, image yang salah, pengujian sistem seperti penyimpanan data, dan lain-lain.

6. Implementation

Tahapan ini adalah tahap mengimplementasikan sistem yang baru dan menjamin bahwa sistem yang baru tersebut dapat berjalan dengan optimal.

7. Maintenance

Tahapan ini adalah tahap akhir untuk mengevaluasi kinerja sistem, apakah sesuai dengan keinginan user atau tidak. Pada bagian akhir tahap ini juga dilakukan kontrol secara berkala dan pembenahan. 
RQ3. Apa kelemahan dari metode yang dipakai untuk menyelesaikan pengembangan sistem informasi tersebut?

System Development Life Cycle (SDLC) atau metodologi Structured Systems Analysis \& Design (SSAD) yang di Indonesia dikenal sebagai analisis dan desain sistem dengan metode terstruktur. Adapun kekurangan dari metode SSAD ini yaitu:

1. SSAD berorientasi utama pada proses, sehingga mengabaikan kebutuhan non-fungsional.

2. Sedikit sekali manajemen langsung terkait dengan SSAD.

3. Prinsip dasar SSAD merupakan pengembangan non-iterative (waterfall), akan tetapi kebutuhan akan berubah pada setiap proses.

4. Interaksi antara analisis atau pengguna tidak komprehensif, karena sistem telah didefinisikan dari awal sehingga tidak adaptif terhadap perubahan (kebutuhan-kebutuhan baru).

5. Selain dengan menggunakan desain logic dan DFD, tidak cukup tool yang digunakan untuk mengkomunikasikan dengan pengguna, sehingga sangat sulit bagi pengguna untuk melakukan evaluasi.

6. Pada SSAD sulit sekali untuk memutuskan ketika ingin menghentikan dekomposisi dan mulai membuat sistem.

7. SSAD tidak selalu memenuhi kebutuhan pengguna.

8. SSAD tidak dapat memenuhi kebutuhan terkait bahasa pemrograman berorientasi objek, karena metode ini memang didesain untuk mendukung bahasa pemrograman terstruktur [15].

\section{Kesimpulan}

Berdasarkan hasil penelitian yang telah dilakukan, dapat diambil beberapa kesimpulan sebagai berikut:

1. Mengacu kepada hasil SLR yang penulis lakukan pada jurnal yang dipublikasi dari tahun 2013-2018, platform yang dominan dibahas dalam penelitian SLR ini adalah web based.

2. Berdasarkan hasil dari SLR yang dilakukan pada publikasi jurnal, dari tahun 2013-2018 metode yang dominan digunakan adalah metode terstruktur.

3. Metode SLR dapat digunakan untuk mengidentifikasi platform dan metode pengembangan sistem informasi di Indonesia (2013-2018).

\section{Referensi}

[1] Krismiaji, Sistem Informasi Akuntansi, Keempat. Yogyakarta: UPP STIM YKPN, 2015.

[2] N. H. Cahyana, B. Yuwono, and A. Y. Asmoro, "PENGEMBANGAN SISTEM INFORMASI PERSEDIAAN BARANG BERBASIS WEB DI PT. PUTERA AGUNG SETIA,” Semin. Nas. Inform., vol. 1, no. 4, Jul. 2015.

[3] S. Kosasi, "Penerapan Rapid Application Development Dalam Sistem Perniagaan Elektronik Furniture," Citec J., vol. 2, no. 4, pp. 265-276, 2015.

[4] E. A. Hayat, E. Retnadi, and E. Gunadhi, "Perancang Sistem Informasi Kependudukan Berbasis Web," J. Algoritm., vol. 11, no. 1, 2014.

[5] B. Kitchenham, O. Pearl Brereton, D. Budgen, M. Turner, J. Bailey, and S. Linkman, "Systematic literature reviews in software engineering - A systematic literature review," Information and Software Technology, vol. 51, no. 1. Elsevier, pp. 7-15, Jan-2009.

[6] B. R. Barricelli, F. Cassano, D. Fogli, and A. Piccinno, "End-user development, end-user programming and end-user software engineering: A systematic mapping study," J. Syst. Softw., vol. 149, pp. 101-137, Mar. 2019.

[7] M. Razavian, B. Paech, and A. Tang, "Empirical research for software architecture decision making: An analysis," J. Syst. Softw., vol. 149, pp. 360-381, 2019.

[8] N. Kühl, M. Goutier, A. Ensslen, and P. Jochem, "Literature vs. Twitter: Empirical insights on customer needs in e-mobility," J. Clean. Prod., vol. 213, pp. 508-520, 2019.

[9] Lusiana and M. Suryani, "Metode SLR untuk Mengidentifikasi Isu-Isu dalam Software Engineering," SATIN (Sains dan Teknol. Informasi), vol. 3, no. 1, 2014.

[10] R. T. S. Hariyati, "Mengenal Systematic Review Theory dan Studi Kasus," J. Keperawatan Indones., vol. 13, no. 2, pp. 124-132, 2010.

[11] A. Solichin and Z. A. Hasibuan, "Pemodelan Arsitektur Teknologi Informasi Berbasis Cloud

Triandini, Jayanatha, Indrawan, Putra, Iswara (Metode Systematic Literature Review untuk Identifikasi Platform dan Metode Pengembangan Sistem Informasi di Indonesia) 
Computing Untuk Institusi Perguruan Tinggi Di Indonesia,” Semantik, vol. 2, no. 1, pp. 10-16, Jun. 2012.

[12] R. Law, "Evaluation of hotel websites: Progress and future developments (invited paper for 'luminaries' special issue of International Journal of Hospitality Management)," Int. J. Hosp. Manag., vol. 76, pp. 2-9, Jan. 2019.

[13] R. Aswani, A. K. Kar, P. V. Ilavarasan, and Y. K. Dwivedi, "Search engine marketing is not all gold: Insights from Twitter and SEOClerks," Int. J. Inf. Manage., vol. 38, no. 1, pp. 107-116, Feb. 2018.

[14] P. Ragunath, S. Velmourougan, P. Davachelvan, S. Kayalvizhi, and R. Ravimohan, "Evolving A New Model (SDLC Model-2010) For Software Development Life Cycle (SDLC)," Int. J. Comput. Sci. Netw. Secur., 2010.

[15] I. Jadalowen, "Structured Analysis and Structured Design (SSAD) Summary," Softw. Eng. Res. Netw. 